\title{
Old nest material functions as an informative cue in making nest-site selection decisions in the European Kestrel (Falco tinnunculus)
}

Mingju $E^{1}$, Tuo Wang ${ }^{2}$, Shangyu Wang ${ }^{3}$, Ye Gong ${ }^{1,4}$, Jiangping Yu ${ }^{1,4}$, Lin Wang ${ }^{5}$, Wei Ou ${ }^{6}$ and Haitao Wang ${ }^{1,7^{*}}$ (D)

\begin{abstract}
Background: For secondary cavity-nesting bird species that do not add lining materials to nests, the presence of old nest material or organic remains that have accumulated within nest cavities from previous breeding events may be a cue of nest-site quality. These materials potentially contain information about past breeding success in con- and heterospecifics and may improve the thermal insulation of eggs during incubation. However, few studies have addressed whether the presence of old nest materials serves as a cue for cavity-nesting raptors when choosing specific nest sites.

Methods: We conducted a 9-year nest box experiment to test whether old nest materials from con- and heterospecifics serve as informative cues to the European Kestrel (Falco tinnunculus) when making nest selection decisions, as this species uses nest boxes without adding nesting material.

Results: The presence of old nest materials and entrance size best discriminated nest boxes occupied by European Kestrels from unoccupied boxes. Nest boxes containing conspecific organic remains, artificial dry leaf and branch material, and material left behind by Great Tits (Parus major) were reused at higher rates, especially those containing conspecific nest material, than nest boxes containing true or simulated nest materials from predators. In 2010, no single nest box was occupied by the same banded individual that occupied the box in the previous year (10 females and 2 males were banded in 2009).

Conclusions: European Kestrels preferred nest boxes containing old nest material over empty boxes, which is consistent with previous findings that they exploit con- and heterospecific cues when deciding where to settle and breed, as old nest or organic material provides substrate for incubating females. Kestrels may be able to assess the predation risks associated with a specific nest site based on experience or the presence of prey remains. The repeated use of nest boxes across breeding seasons by kestrels cannot be entirely ascribed to philopatry. This study provides evidence that old nest materials are potentially used as informative cues when making nest-site selection decisions in European Kestrels.
\end{abstract}

Keywords: European Kestrel, Informative cue, Nest box, Nest materials

\footnotetext{
*Correspondence: wanght402@nenu.edu.cn

${ }^{1}$ Jilin Engineering Laboratory for Avian Ecology and Conservation

Genetics, School of Life Sciences, Northeast Normal University,

Changchun 130024, China

Full list of author information is available at the end of the article
}

(c) The Author(s) 2019. This article is distributed under the terms of the Creative Commons Attribution 4.0 International License (http://creativecommons.org/licenses/by/4.0/), which permits unrestricted use, distribution, and reproduction in any medium, provided you give appropriate credit to the original author(s) and the source, provide a link to the Creative Commons license, and indicate if changes were made. The Creative Commons Public Domain Dedication waiver (http://creativecommons.org/ publicdomain/zero/1.0/) applies to the data made available in this article, unless otherwise stated. 


\section{Background}

Most animals face heterogeneous and, to a certain extent, unpredictable environmental factors in their habitats. These factors often affect components of fitness, such as the intensity of predation and competition, abundance of food and nest resources, and microclimatic conditions (Orians and Wittenberger 1991; Frey et al. 2016), hence affecting fitness-related decisions during their lifetimes. For birds, one such important decision is where to breed (Wiens 1976), which may have ramifications for an individual's future reproductive fitness.

There is growing evidence that birds are able to assess habitat quality to make breeding habitat decisions by using various informative cues. Empirical studies have described several possible cues that affect the selection of breeding habitat in birds, such as their own reproductive success (Marzluff 1988; Beletsky and Orians 1991; Switzer 1997; Lagrange et al. 2017); information on environmental factors affecting breeding success (Nilsson et al. 1991; Brown and Brown 1997; Ruth and Skagen 2017); information from con- and heterospecifics, such as their presence and activities (Pärt and Doligez 2003; Forsman et al. 2008; Hromada et al. 2008); and the local reproductive success of conspecifics and heterospecifics (Aparicio et al. 2007; Parejo et al. 2008). In some cases, however, such information cues may be unavailable to birds at the beginning of a nesting season, preventing them from being able to judge the quality of the nesting habitat. Personal information on previous reproductive success is not available to individuals who have yet to breed in a particular location (Citta and Lindberg 2007). Furthermore, the vegetation that serves to conceal nests from predators or to support nests may not be fully developed, and potential predators may not be present at densities or in locations typical of those during the nesting period (Erckmann et al. 1990). Information on local reproductive success will be available only at the end of a breeding season and thus can be used for breeding habitat selection only in the following year (Danchin et al. 1998). In addition, the presence and activities of already settled conspecific and heterospecific individuals may be available as cues for future avian breeding activities.

Nest material can provide several types of favourable conditions for thermoregulation. Nest material can form concave bowls to gather eggs to keep the maximum amount of the egg surface in contact with the insulating medium, cover eggs well during incubation recesses, and provide a sufficient cushion between the eggs and the floor of the nesting box, especially in environments with relatively extreme weather conditions (Hilton et al. 2004; Mainwaring et al. 2014). Due to their long-lasting nature, natural cavities and nest boxes often contain old nest material or other materials, such as the faeces of nestlings, egg shells, down feathers, and even the remains of prey from previous seasons; these factors may facilitate nest-site selection in secondary cavity-nesting birds. In addition, the accumulation of old nest material could provide particularly precise information on previous breeding history because it integrates several potential cues into a single cue. For example, natural cavities or nest boxes containing nest material may provide information on successful or aborted breeding history, whereas empty nest cavities or boxes are often a result of nest predation or poor nest-site quality and may function as a cue for nest-site selection among cavity-nesting birds that reuse the nests of con- or heterospecifics (Orell et al. 1993; Olsson and Allander 1995; Johnson 1996; Mazgajski 2007; Sumasgutner et al. 2014). On the other hand, old nest material provides good over-wintering and developmental conditions for various groups of ectoparasites; in this respect, there may be costs associated with the utilization of nests containing nest material, as doing so may increase the rates of infection by parasites and pathogens (Rendell and Verbeek 1996; Saino et al. 1998). In such situations, birds may avoid nests containing old nest material. Hence, secondary cavity-nesting birds must face a trade-off between these problems when selecting a particular nest every year.

No consistent pattern has been found so far to link the presence or absence of old nest materials with nest-site selection by birds, even in a single species (Mazgajski 2007). Studies on the pressure exerted by ectoparasites and pathogens, as well as that by predators, suggest that secondary cavity nesters may avoid sites with old nest materials (Nilsson et al. 1991; Proctor and Owens 2000; Bouslama et al. 2002; Sorace et al. 2004), whereas studies concerning the potential positive functions of old nest materials (e.g., time and energy savings or serving as an informative cue for breeding birds) have suggested that secondary cavity nesters may show a preference for sites with old nest material (Davies et al. 1994; Olsson and Allander 1995; Sumasgutner et al. 2014; Podofillini et al. 2018). However, the influences of old nest materials on nest-site selection have been studied almost exclusively with small cavity-nesting passerines (see Mazgajski 2007), while the influences on cavity-nesting non-passerines remain largely unclear, leading to the disregard of a different behavioural trait that exists between most cavity-nesting passerines and non-passerines. Small secondary cavity-nesting passerines build and rebuild their nests (Mazgajski 2007), whereas most cavity-nesting non-passerines, such as falcons and owls, do not add nest material to their occupied nests (Zhou et al. 2009; López et al. 2010). These differences may lead to different reactions between cavity-nesting passerines and non-passerines to old nest materials during nest-site selection. 
Raptors appear to make wide use of public, social, and environmental information for dispersal, colony-site settlement decisions and nest-site selection, with the breeding success of conspecifics being an important cue (Serrano et al. 2001, 2003; Aparicio et al. 2007; Sumasgutner et al. 2014; Podofillini et al. 2018). However, few studies have addressed whether the presence of old nest materials serves as a cue for the selection of specific nest sites among members of a breeding population (Sumasgutner et al. 2014; Podofillini et al. 2018). We performed a nest box selection experiment to test whether nest material serves as an informative cue in nest-site selection in the European Kestrel (Falco tinnunculus), a species that uses nest boxes without adding its own nesting materials. We predicted that if the presence of old nest materials serves as an informative cue regarding previous breeding history or nest quality, then European Kestrels should select nest boxes based on the presence of nest materials and avoid empty nest boxes.

\section{Methods \\ Field site}

Data were collected during nine breeding seasons (2004-2012) at the Zuojia Nature Reserve $\left(126^{\circ} 1^{\prime}-127^{\circ} 2^{\prime}\right.$ $\left.\mathrm{N}, 44^{\circ} 6^{\prime}-45^{\circ} 5^{\prime} \mathrm{E}\right)$. Our study plots covered an area of $\sim 21 \mathrm{~km}^{2}$ at 200 to $530 \mathrm{~m}$ a.s.l. The climate of the study area is temperate and subject to the eastern monsoon climate, which is characterized by hot, dry summers and cold, snowy winters. The forest type within the reserve is secondary growth; trees are approximately 40 to 50 years of age (Deng et al. 2011). The study area at the time of the observations was covered by approximately $35 \%$ open habitat and $65 \%$ forest habitats. The vegetation within the study area was diverse, although the existing forest was secondary, and the average height of the trees ranged from 12.7 to $16.2 \mathrm{~m}$. One hundred ninety bird species were recorded in Zuojia, and the species were dominated by passerines ( 101 species) and raptors ( 28 species) (Geng et al. 2009).

\section{Field methods}

Nest boxes were constructed from rough-cut boards and assembled with exterior nails or deck screws. The roof of each nest box was designed to be waterproof, and the bottom was designed to permit drainage. The roof and body of each nest box were attached with hinges, and a hook and ring were used to prevent the roof from being opened unintentionally. A slat of wood was nailed to the back of every nest box to provide a ledge for installation. The internal dimensions of all boxes were as follows: $50 \mathrm{~cm}$ height with a $35 \mathrm{~cm} \times 35 \mathrm{~cm}$ floor and a 10.5 , 12.5 or $15.0 \mathrm{~cm}$ diameter entrance hole near the top. The nest boxes were placed approximately 4.4-13.2 m above the ground with $50-150 \mathrm{~m}$ between adjacent boxes and were all placed in similar habitats. We added new boxes or replaced destroyed and unusable boxes with new ones each year. A total of 219 new nest boxes were installed in the study, and 561 artificial nest boxes in total were monitored from 2004 to 2012. Nest-entrance orientation was determined for all nests by recording the direction of the line from the centre of the nest through the centre of the entrance with an ordinary compass.

We added dry leaves (ca 1.5 to $2 \mathrm{~cm}$ layer) to 81 boxes and simulated nest materials of the Eurasian Red Squirrel (Sciurus vulgaris) to 43 boxes and left 95 boxes empty during installation. Six species of cavity-nesting nonpasserines occupied the nest boxes to breed during the study, including the European Kestrel, Mandarin Duck (Aix galericulata), Ural Owl (Strix uralensis), Dollarbird (Eurystomus orintals), Collared Scops Owl (Otus lettia) and Oriental Scops Owl (Otus sunia). In addition, the Great Tit (Parus major) and Eurasian Red Squirrel also occupied the nest boxes to breed. Most old nest boxes had never been cleaned after their original deployment; hence, old nest materials derived from previous breeding events were spread across the floors of the nest boxes. We categorized the nest material into 7 types according to the manipulation methods and previous dwelling species: empty (cleaned boxes were included), dry leaves and branches, conspecific (European Kestrel), tit (Great Tit), squirrel (Eurasian Red Squirrel), simulated squirrel, and others (nest materials from Mandarin Ducks, Ural Owl and Dollarbirds were combined because of small sample size). The nature of the nest materials in a box were changed after being used by the different species: the Great Tit added large amounts of moss to the nests; the Mandarin Duck left down feathers and egg shells, the European Kestrel left pellets and sometimes the remains of prey, the Ural Owl left the remains of prey, the Dollarbird left nestling faeces, and the Eurasian Red Squirrel added slender grasses and soft plant fibres to the nests. We recategorized the type of nest material in a box if the nature of the old nest material changed as a result of being used by different species between consecutive breeding seasons. However, three nests associated with adult kestrels that were preyed upon by Ural Owls, which left a layer of feathers inside the boxes, were still categorized as conspecific. In addition, the nest materials in 29 boxes were recategorized because they were used two times by different species within the same breeding season due to nest usurpation or nest reutilization after breeding failure. Because some species of raptors show high nest-site fidelity (Serrano et al. 2001; Burnham et al. 2009), nest box preferences can be affected by previous experience and recognition of the previous year's nest sites. Ten female and 2 male kestrels were caught using 
a remote-controlled trap that blocked the entrance to the nest box when it was occupied. Upon capture, the kestrels were banded with rings to test whether nest-site fidelity played a role in conspecific nest reutilization in 2009 and 2010. All captured individuals were banded with a uniquely numbered aluminium ring as well as a unique colour band combination. The handling time was minimal ( 3 min maximum), and all birds were released near their nests after the procedure. No bird abandoned its nest after capture. In addition, 21 old boxes used twice by kestrels in succession were cleaned prior to the breeding seasons to examine the role of nest material as a conspecific cue for nest reutilization. All other old boxes containing nest material (from both birds and mammals) from previous breeding seasons were not manipulated with the exception of the addition of dry leaves and branches to 54 unused old empty boxes.

The nest boxes were checked at intervals of 5-7 days to determine occupancy, and the types of nest material in all boxes were recorded. We classified boxes with at least one egg as occupied. The European Kestrel is a resident species that breeds earlier than migrant species in our study area. The earliest clutch initiation dates that were recorded were 13 March for the European Kestrel, 22 April for the Mandarin Duck (Deng et al. 2011), 6 June for the Dollarbird, 10 May for the Collared Scops Owl and 31 May for the Oriental Scops Owl. In addition, the European Kestrels usually occupied the nest boxes for at least 10 days before laying eggs (personal observation); they also exhibited the ability to drive the current occupant of a nest box away, as one case of this species usurping a Mandarin Duck-occupied nest was recorded during this study (Gong et al. 2018). Therefore, a box recorded as unoccupied represented one that was not used by a kestrel in a specific year of the study.

\section{Statistical analysis}

We counted the numbers of boxes containing different types of nest material separately and combined the data from the 9 years to calculate the occupation rates by European Kestrels. The nest boxes occupied by Ural Owls were excluded from the analysis because the breeding season of this species occurs earlier than that of the European Kestrel.

To determine which factor best discriminated between occupied and unoccupied nest boxes, we used generalized linear-mixed models (GLMM) with a logit link and binomial error distribution. The dependent variable was occupation by the European Kestrel ( 1 and 0 for occupation and no occupation, respectively). The independent variables in the full model included the absolute age of the boxes (new boxes were designated as 1 , old nests as 2 ), nest box height from the ground, presence or absence of nesting material (absence $=0$, presence $=1$ ), entrance size of the boxes, entrance orientation of the boxes, and the interaction of the latter two independent variables. Monitoring year and nest box ID were included as random factors to avoid pseudoreplication by incorporating repeated measures. We selected the best model using a backward stepwise elimination approach with variables retained in the model at $p<0.05$. The $R^{2}$ values of the GLMMs were calculated using the MuMIn package. A multinomial logistic regression (multinom function in the nnet $\mathrm{R}$ package) was used as the statistical method to identify the effect of the type of nest material. Occupation by the European Kestrel ( 1 and 0 for occupation and no occupation, respectively) was included as the dependent variable, and the type of nest material $(1=$ empty; $2=$ conspecific; $3=$ tit; $4=$ squirrel; $5=$ dry leaves and branches; $6=$ simulated squirrel; $7=$ others) was included as the independent variable. Likelihood ratio tests were used to obtain $p$ values. All statistical analyses were performed in R 3.5.3 (R Core Development Team, http:// cran.r-project.org/).

\section{Results}

A total of 119 boxes were occupied by European Kestrels during this study (Table 1 ). The presence of nesting material (GLMM: $\chi^{2}=17.691, p=0.000$ ) and entrance size of the boxes (GLMM: $\chi^{2}=20.192, p=20.192$ ) discriminated nest boxes occupied by European kestrels from unoccupied boxes, while the absolute age of the boxes, nest box height from the ground, entrance orientation and their interactions were not significantly associated with nest occupation (Table 2). The occupation rates (22.04\%) of boxes containing different types of nest material significantly varied in this study (multinomial logistic regression, $\left.\chi_{6}^{2}=117.670, p<0.001\right)$. European Kestrels chose boxes containing conspecific organic remains (pellets and the remains of prey), artificial material of dry leaves and branches, and material from tits at higher rates than those containing material from the other categories: $60.4 \%$ (58 out 96 ), $30.1 \%$ ( 22 out 71 ), and $28.6 \%$ ( 14 out 49), respectively (Fig. 1). The reutilization rates were $10.7 \%$ ( 6 out 56 boxes) for the boxes containing squirrel nest material, $7.1 \%$ (13 out of 182 ) for empty boxes, $7.0 \%$ (3 out of 43) for boxes containing simulated squirrel nest materials, and 7.3\% (3 out of 41) for boxes containing other materials. Among the boxes containing other types of old nest material, only one containing material from a Mandarin Duck and two containing material from dollarbirds were reused, and no boxes containing material from owls were selected. In 2010, no single nest box was occupied by the same banded individual that used the box in the previous year. 
Table 1 Number of nest boxes and occupied boxes from 2004 to 2012

\begin{tabular}{|c|c|c|c|c|c|c|c|c|c|}
\hline \multirow[t]{2}{*}{ Year } & \multirow{2}{*}{$\begin{array}{l}\text { No. of nests } \\
\text { (new/old) }\end{array}$} & \multicolumn{7}{|c|}{ With nest materials } & \multirow{2}{*}{$\begin{array}{l}\text { No. } \\
\text { of occupied } \\
\text { nests boxes }\end{array}$} \\
\hline & & WNM & EKM & GTM & ERSM & ANM & SESM & OTM & \\
\hline 2004 & $61(61 / 0)$ & 19 & 0 & 2 & 0 & 40 & 0 & 0 & 21 \\
\hline 2005 & $56(15 / 41)$ & 21 & 11 & 4 & 5 & 12 & 0 & 3 & 16 \\
\hline 2006 & $58(8 / 50)$ & 19 & 17 & 10 & 6 & 6 & 0 & 0 & 17 \\
\hline 2007 & $74(12 / 62)$ & 30 & 22 & 11 & 5 & 3 & 0 & 3 & 22 \\
\hline 2008 & $74(9 / 65)$ & 19 & 17 & 10 & 16 & 2 & 0 & 10 & 15 \\
\hline 2009 & $68(8 / 60)$ & 20 & 12 & 5 & 15 & 0 & 9 & 7 & 11 \\
\hline 2010 & $52(12 / 40)$ & 20 & 10 & 10 & 3 & 1 & 2 & 6 & 14 \\
\hline 2011 & $33(7 / 26)$ & 14 & 7 & 0 & 3 & 1 & 2 & 6 & 1 \\
\hline 2012 & $64(59 / 5)$ & 20 & 0 & 5 & 3 & 8 & 24 & 4 & 1 \\
\hline
\end{tabular}

Nest materials were categorized into seven types based on previous breeders and manipulation treatments in the study: without nest material (WNM), old European Kestrel nest material (EKM), Great Tit nest material (GTM, both new and old), old Eurasian Red Squirrel nest material (ERSM), artificial nest material of dry leaves and branches (ANM), simulated nest material of Eurasian Red Squirrel (SESM), and other types of nest material (OTM, mainly including old Mandarin Duck and Ural Owl nest materials)

Table 2 GLMMs used to determine the factors that affected whether European Kestrel occupied or did not occupy the boxes (Final model $R_{m}^{2}=0.183, R_{c}^{2}=0.554$, $n=540$ )

\begin{tabular}{lccccc}
\hline Factors & df & Estimate & $\mathbf{x}^{\mathbf{2}}$ & SE & $\boldsymbol{p}$ \\
\hline Intercept & 1 & -8.6565 & 16.0292 & 2.162 & 0.000 \\
$\quad$ With/without nest material & 1 & 1.736 & 17.691 & 0.394 & 0.000 \\
$\quad$ Entrance size & 1 & 0.394 & 20.192 & 0.162 & 0.015 \\
$\begin{array}{l}\text { Rejected term } \\
\text { Entrance size } \times \text { entrance }\end{array}$ & 1 & 0.094 & 0.371 & 0.156 & 0.542 \\
$\quad$ orientation & & & & & \\
$\quad \begin{array}{l}\text { Nest box height from ground } \\
\text { Entrance orientation }\end{array}$ & 1 & -0.007 & 0.038 & 0.035 & 0.845 \\
$\quad$ Absolute age of box & 1 & 0.190 & 0.372 & 0.312 & 0.549 \\
\hline
\end{tabular}

\section{Discussion}

The majority of published papers addressing old nest material are related to nest-site selection (Orell et al. 1993; Mazgajski 2003; Stanback and Rockwell 2003; Tomás et al. 2007; Podofillini et al. 2018); however, no consistent correlation has been found between the presence/absence of nest material and nest-site selection in birds, indicating broad interpopulation and interspecific differences in preference patterns (see Mazgajski 2007 for a review). A preference for nest boxes containing old nest material has been observed in some passerine species (Orell et al. 1993; Davies et al. 1994; Olsson and Allander 1995), as well as some raptor species (Negro and Hiraldo 1993; Sumasgutner et al. 2014; Podofillini et al. 2018). The results of our study indicate that European Kestrels show a preference for boxes containing nest material over empty boxes. One possible explanation for this result is that kestrels exploit cues about previous breeding

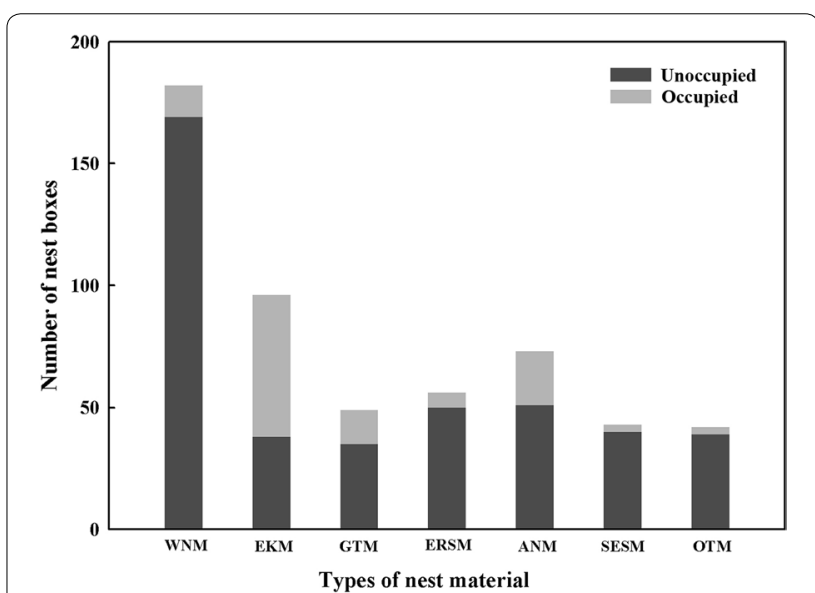

Fig. 1 Nest boxes containing different types of nest material occupied by the European Kestrel. Nest materials were categorized into seven types based on previous breeders and manipulation treatments in the study: without nest material (WNM), old European Kestrel nest material (EKM), Great Tit nest material (GTM, both new and old), old Eurasian Red Squirrel nest material (ERSM), artificial nest material of dry leaves and branches (ANM), simulated Eurasian Red Squirrel nest material (SESM), and other types of nest material (OTM, mainly including old Mandarin Duck and Ural Owl nest materials)

attempts by con- and heterospecifics when choosing a nest or colony site (Negro and Hiraldo 1993; Serrano et al. 2003; Aparicio et al. 2007). Another possible explanation is that nest material may provide a nest substrate for incubating females (Podofillini et al. 2018).

Gathering information is a prerequisite for animals to make optimal decisions under variable conditions (Dall et al. 2005). The presence of old nest material within a nest box does in fact represent an informative cue about previous breeding performance; nest boxes containing 
such material may be preferred as they may be perceived as more suitable than similar cavities for which no sign of previous reproduction is evident (Sumasgutner et al. 2014). In this study, nest boxes containing conspecific organic remains were reused by European Kestrels at the highest rates. Information seems to be transferred between kestrels by using a layer of pellets and other prey remains as an indirect cue of previous breeding success (Sumasgutner et al. 2014). Kestrels avoided reusing boxes occupied by Ural Owls and Mandarin Ducks during previous breeding seasons. A possible reason why the kestrels avoided reusing old Mandarin Duck nests could be that those nests contained eggshell fragments and scattered feathers, leading the kestrels to not obtain accurate information about breeding success or predation. In addition to rodents, Ural Owls have been found to prey on birds such as European Kestrel, Black-billed Magpies (Pica pica) and Eurasian Jays (Garrulus glandarius). In this study, the old nests of Ural Owls were therefore found to contain prey remains, such as the feathers and bones of these birds, which may convey discrete information about the presence of predators (Galef and Giraldeau 2001). In addition, the reutilization rates for boxes containing squirrel and simulated squirrel nest material were low; we speculate that in the absence of prey remains, kestrels may assess the predation risk based on personal experience. Squirrels are widely cited as dominant and abundant nest predators in forest habitats (Martin 1988; Reitsma et al. 1990). In our study, European Kestrel eggs in two nests were preyed upon by Eurasian Red Squirrels, and we witnessed a natural encounter in which a male European Kestrel chased a Eurasian Red Squirrel away from its active nest. Therefore, the use of personal experience of predation to measure predation risk based on nest materials and select breeding sites accordingly is likely adopted by the European Kestrel.

Studies have demonstrated that nest material can provide several types of favourable conditions for thermoregulation, especially in environments with relatively extreme weather conditions (Hilton et al. 2004; López et al. 2010). For secondary cavity-nesting bird species, old nest material that has accumulated within nest cavities during previous breeding events may be a cue indicating nest-site quality, as such material may improve the thermal insulation of eggs during incubation. Incubating birds, especially those that lay eggs directly on the substrate without lining their nest cavity, are therefore expected to preferentially lay eggs on those substrates that minimize the energetic costs of incubation (Deeming 2002; Mainwaring et al. 2014). Boxes containing old kestrel nests are usually covered with a layer of pellets and prey remains, while the old Great Tit nests mostly consist of mosses along with feathers and hairs (Gibb
1950; Ondrušová and Adamík 2013), which may be helpful in keeping eggs together, reducing heat loss, increasing the incubation efficiency, and ultimately lowering the energetic costs of incubation (Mainwaring et al. 2014). The presence of artificial nesting material composed of dry leaves and branches may affect the reutilization of nest boxes in the same way. In this study, the European Kestrels began to lay eggs in the middle of March, when the local ambient temperature was $-1.6 \pm 2.1{ }^{\circ} \mathrm{C}$, the temperature was $8.4 \pm 1.6{ }^{\circ} \mathrm{C}$ in April and $15.6 \pm 1.3^{\circ} \mathrm{C}$ in May (1987 to 2006, http://www.ccafs-climate.org/data/). These temperatures are far lower than the fundamental incubation temperature; thus, thermoregulation may be essential for egg survival and embryo development in non-passerine birds that use nest boxes without added nesting material. The presence of old nest material or the addition of artificial material to a box may improve thermoregulation and hence the attractiveness or quality of a box.

The reutilization of cavities or nest boxes containing old nest material in secondary cavity-nesting birds may be a consequence of low nest-site availability (Aitken et al. 2002). Furthermore, within our study area, kestrels breed earlier than other cavity-nesting non-passerines except the Ural Owl and may alternatively use old Blackbilled Magpie (Pica pica) nests or natural cavities to breed (Zhou et al. 2009). Therefore, we reasoned that the preference of the kestrels to use nest boxes already containing nest material is not a consequence of low nest-site availability.

The utilization of the same nest site over multiple years is described as nest-site fidelity (Lindberg and Sedinger 1997; Stanback and Rockwell 2003). Nest-site fidelity in birds may involve several factors. Competition for nest sites may cause individuals to return to a previous breeding site, especially among cavity-nesting birds (Dow and Fredga 1983). Previous breeding experience is another factor that influences nest-site fidelity in birds. Successfully nesting individuals are more likely to return to the same nest site than individuals who were not successful (Beletsky and Orians 1991; Gowaty and Plissner 1997; Stanback and Dervan 2001; Johannesen et al. 2002; Styrsky 2005). Other factors, such as age, sex, breeding density, habitat and nest characteristics, have also been found to be related to nest-site fidelity (Switzer 1993; Dubois et al. 1998; Pyle et al. 2001; Beheler et al. 2003; Vergara et al. 2006). The reuse of the same nest box over multiple years was not observed among the European Kestrels in this study; however, the repeated use of nest boxes across multiple breeding seasons by kestrels cannot be entirely ascribed to philopatry. No single nest box was occupied in 2010 by the same banded individual from the previous year; however, there was a lack of banding data across 
years. Furthermore, the kestrels avoided using the same box when nest material was removed, indicating that the nest material plays an important role in nest-site selection even if nest-site fidelity cannot be excluded.

Cavity-dwelling bird species tend to prefer entrance holes that are closely matched to their body size to minimize predation risk (Wesolowski 2002). The fact that European Kestrels selected nest boxes with wide entrance diameters may be caused by their body size. However, the kestrels used nest boxes with entrance diameters greater than that required, allowing access by the nest owners while also potentially providing access to a wide range of predators. Whether this phenomenon has fitness consequences for nesting kestrels could be determined by evaluating the influence of entrance diameter on the outcome of reproductive success.

\section{Conclusions}

Our results suggest that European Kestrels prefer nest boxes containing old nest materials, especially those of conspecifics, over empty boxes. The presence of old nest material or organic materials from previous nesting attempts in nest boxes may play an important role in making nest-site selection decisions in kestrels. These decisions are consistent with exploiting con- and heterospecific cues when deciding where to settle and breed, as old nest material or organic material provides a comfortable nest substrate for incubating females. Kestrels may be able to assess the predation risks at specific nest sites according to personal experience or the presence of prey remains, as nest boxes containing true or simulated nest material from predators were avoided. The repeated use of nest boxes across breeding seasons by the kestrel cannot be entirely ascribed to philopatry. We propose that the manipulation of nest material may represent an effective way to increase the nest box occupation rate by European Kestrels.

\section{Acknowledgements}

We thank Xiangjing Zhang, Yonghong Pan, Xingyang Wang, Jin Lu, Hui Wu, Xiaohui Wang, Di Yao, Xiang Cui and Jiawei Zhang for assistance in the field and Badru-Deen Barry and Mohamed Jabbie for helping us to revise the manuscript in English.

\section{Authors' contributions}

HW conceived and designed the study. ME, TW, YG, and LW conducted the experiments in the field. ME, SW, WO and HW analysed the data and wrote the paper. All authors read and approved the final manuscript.

\section{Funding}

The study was financed by the National Natural Science Foundation of China (No. 31770419, 31272331, 30970375, 30400047 to HW) and the Postdoctoral Program of Agricultural Science and Technology Innovation Center in Northeast China (No. 150482 to WO).

\section{Availability of data and materials}

The datasets used in the present study are available from the corresponding author on reasonable request.
Ethics approval and consent to participate

The present study complies with the current laws of China. Fieldwork was carried out under the permission from the Zuojia Nature Reserve, Jilin, China. Experimental procedures were permitted by the National Animal Research Authority in Northeast Normal University (Approval Number: NENU-20080416) and the Forestry Bureau of Jilin Province of China (Approval Number: [2006]178).

\section{Consent for publication \\ Not applicable.}

\section{Competing interests}

The authors declare that they have no competing interests.

\section{Author details}

1 Jilin Engineering Laboratory for Avian Ecology and Conservation Genetics, School of Life Sciences, Northeast Normal University, Changchun 130024, China. ${ }^{2}$ Northeast Normal University Natural History Museum, Northeast Normal University, Changchun 130024, China. ${ }^{3}$ School of Life Sciences, Jilin University, Changchun 130012, China. ${ }^{4}$ Ministry of Education Key Laboratory of Vegetation Ecology, School of Life Sciences, Northeast Normal University, Changchun 130024, China. ${ }^{5}$ Key Laboratory of Wetland Ecology and Environment, Northeast Institute of Geography and Agroecology, Chinese Academy of Sciences, Changchun 130102, China. ${ }^{6}$ Jilin Academy of Agricultural Sciences, Changchun 130033, China. ${ }^{7}$ Jilin Provincial Key Laboratory of Animal Resource Conservation and Utilization, School of Life Sciences, Northeast Normal University, Changchun 130024, China.

Received: 5 May 2019 Accepted: 31 October 2019

Published online: 09 November 2019

\section{References}

Aitken KEH, Wiebe KL, Martin K. Nest-site reuse patterns for a cavity-nesting bird community in interior British Columbia. Auk. 2002;119:391-402.

Aparicio JM, Bonal R, Munoz A. Experimental test on public information use in the colonial Lesser Kestrel. Evol Ecol. 2007;21:783-800.

Beheler AS, Rhodes OE, Weeks PH. Breeding site and mate fidelity in Eastern Phoebes (Sayornis phoebe) in Indiana. Auk. 2003;120:990-9.

Beletsky LD, Orians GH. Effects of breeding experience and familiarity on site fidelity in female red-winged blackbirds. Ecology. 1991;72:787-96.

Bouslama Z, Lambrechts MM, Ziane N, Djenidi R, Chabi Y. The effect of nest ectoparasites on parental provisioning in a north-African population of the Blue Tit Parus caeruleus. Ibis. 2002;144:e73-8.

Brown CR, Brown MB. Coloniality in the Cliff Swallow: the effect of group size on social behavior. J Parasitol. 1997;27:751.

Burnham KK, Burnham WA, Newton I. Gyrfalcon Falco rusticolus post-glacial colonization and extreme long-term use of nest-sites in Greenland. Ibis. 2009;151:514-22.

Citta JJ, Lindberg MS. Nest-site selection of passerines: effects of geographic scale and public and personal information. Ecology. 2007;88:2034-46.

Dall SRX, Giraldeau LA, Olsson O, McNamara JM, Stephens DW. Information and its use by animals in evolutionary ecology. Trends Ecol Evol. 2005;20:187-93.

Danchin E, Boulinier T, Massot M. Conspecific reproductive success and breeding habitat selection: implications for the study of coloniality. Ecology. 1998;79:2415-28.

Davies WH, Kalisz PJ, Wells RJ. Eastern bluebirds prefer boxes containing old nests. J Field Ornithol. 1994;65:250-3.

Deeming DC. Avian incubation: behaviour, environment, evolution. Auk. 2002;119:1210-1.

Deng QX, Wang HT, Yao D, Wang XY, E MJ, Wang T, et al. Conspecific brood parasitism and nesting biology of Mandarin ducks Aix galericulata in northeast China. Wilson J Ornithol. 2011;123:479-85.

Dow H, Fredga S. Breeding and natal dispersal of the goldeneye, Bucephala clangula. J Anim Ecol. 1983;52:681-96.

Dubois F, Cezilly F, Pagel M. Mate fidelity and coloniality in waterbirds: a comparative analysis. Oecologia. 1998;116:433-40. 
Erckmann WJ, Beletsky LD, Orians GH, Johnsen T, Sharbaugh S, Antonio C. Old nests as cues for nest-site selection: an experimental test with Redwinged Blackbirds. Condor. 1990;92:113-7.

Forsman JT, Hjernquist MB, Taipale J, Gustafsson L. Competitor density cues for habitat quality facilitating habitat selection and investment decisions. Behav Ecol. 2008;19:539-45.

Frey SJK, Hadley AS, Betts MG. Microclimate predicts within-season distribution dynamics of montane forest birds. Divers Distrib. 2016;22:944-59.

Galef BG, Giraldeau L. Social influences on foraging in vertebrates: causal mechanisms and adaptive functions. Anim Behav. 2001;61:3-15.

Geng R, Zhang X, Ou W, Sun HM, Lei FM, Gao W, et al. Diet and prey consumption of breeding Common Kestrel (Falco tinnunculus) in Northeast China. Prog Nat Sci. 2009;19:1501-7.

Gibb BJ. The breeding biology of the great and blue titmice. Ibis. 1950;92:507-39.

Gong Y, Bibi N, Wang HT. Nest usurpation between Mandarin Duck Aix galericulata and coexisting bird species in nest boxes in a secondary forest, Zuojia Nature Reserve, China. Pak J Zool. 2018;50:1537.

Gowaty PA, Plissner JH. Breeding dispersal of eastern bluebirds depends on nesting success but not on removal of old nests: an experimental study. J Field Ornithol. 1997;68:323-30.

Hilton GM, Hansell MH, Ruxton GD, Reid JM, Monaghan P. Using artificial nests to test importance of nesting material and nest shelter for incubation energetics. Auk. 2004;121:777-87.

Hromada M, Antczak M, Valone TJ, Tryjanowski P. Settling decisions and heterospecific social information use in shrikes. PLoS ONE. 2008;3:e3930.

Johannesen E, Perriman L, Steen $\mathrm{H}$. The effect of breeding success on nest and colony fidelity in the Little Penguin (Eudyptula minor) in Otago, New Zealand. Emu. 2002;102:241-7.

Johnson LS. Removal of old nest material from the nesting sites of house wrens: effects on nest site attractiveness and ectoparasite loads. J Field Ornithol. 1996;67:212-21.

Lagrange P, Gimenez O, Doligez B, Pradel R, Garant D, Pelletier F, et al. Assessment of individual and conspecific reproductive success as determinants of breeding dispersal of female tree swallows: a capture-recapture approach. Ecol Evol. 2017;7:7334-46.

Lindberg MS, Sedinger JS. Ecological consequences of nest site fidelity in Black Brant. Condor. 1997;99:25-38.

López BC, Potrony D, López A, Badosa E, Bonada A, Salo R. Nest box use by boreal owls (Aegolius funereus) in the Pyrenees mountains in Spain. J Raptor Res. 2010;44:40-9.

Mainwaring MC, Hartley IR, Lambrechts MM, Deeming DC. The design and function of birds' nest. Ecol Evol. 2014;4:3909-28.

Martin TE. Processes organizing open-nesting bird assemblages: competition or nest predation? Evol Ecol. 1988;2:37-50.

Marzluff JM. Do pinyon jays alter nest placement based on prior experience? Anim Behav. 1988;36:1-10.

Mazgajski TD. Nest site choice in relation to the presence of old nests and cavity depth in the starling Sturnus vulgaris. Ethol Ecol Evol. 2003;15:273-81.

Mazgajski TD. Effect of old nest material on nest site selection and breeding parameters in secondary hole nesters - a review. Acta Ornithol. 2007:42:1-14.

Negro JJ, Hiraldo F. Nest-site selection and breeding success in the lesser kestrel Falco naumanni. Bird Study. 1993;40:115-9.

Nilsson SG, Johnsson K, Tjernberg M. Is avoidance by black woodpeckers of old nest holes due to predators? Anim Behav. 1991;8:439-41.

Olsson K, Allander K. Do fleas and/or old nest material, influence nest site preference in hole-nesting passerines? Ethology. 1995;101:160-70.

Ondrušová K, Adamík P. Characterizing the mammalian hair present in great tit (Parus major) nests. Bird Study. 2013;60:428-31.

Orell M, Rytkönen S, Ilomäki K. Do pied flycatchers prefer nest boxes with old nest material? Ann Zool Fenn. 1993:30:313-6.

Orians GH, Wittenberger JF. Spatial and temporal scales in habitat selection. Am Nat. 1991:137:S29-49.
Parejo D, Danchin E, Silva N, White JF, Dreiss AN, Avilés JM. Do great tits rely on inadvertent social information from blue tits? A habitat selection experiment. Behav Ecol Sociobiol. 2008;62:1569-79.

Pärt T, Doligez B. Gathering public information for habitat selection: prospecting birds cue on parental activity. Proc R Soc Lond B Biol Sci. 2003;270:1809-13.

Podofillini S, Cecere JG, Griggio M, Curcio A, De Capua EL, Fulco E, et al. Home, dirty home: effect of old nest material on nest-site selection and breeding performance in a cavity-nesting raptor. Curr Zool. 2018;64:693-702.

Proctor H, Owens I. Mites and birds: diversity, parasitism and coevolution. Trends Ecol Evol. 2000;15:358-64.

Pyle P, Sydeman WJ, Hester M. Effects of age, breeding experience, mate fidelity and site fidelity on breeding performance in a declining population of Cassin's auklets. J Anim Ecol. 2001;70:1088-97.

Reitsma LA, Holmes RT, Sherly TW. Effects of removal of red squirrels, Tamiasciurus hudsonicus, and eastern chipmunks, Tamias striatus, on nest predation in a northern hardwood forest: an artificial nest experiment. Oikos. 1990:57:375-80.

Rendell WB, Verbeek NA. Old nest material in nest boxes of tree swallows: effects on nest-site choice and nest building. Auk. 1996;113:319-28.

Ruth JM, Skagen SK. Territory and nest site selection patterns by Grasshopper Sparrows in southeastern Arizona. Condor. 2017;119:469-83.

Saino N, Calza S, Møller AP. Effects of a dipteran ectoparasite on immune response and growth trade-offs in Barn Swallow, Hirundo rustica, nestlings. Oikos. 1998;81:217-28.

Serrano D, Tella JL, Forero MG, Dona'zar JA. Factors affecting breeding dispersal in the facultatively colonial lesser kestrel: individual experience vs conspecific cues. J Anim Ecol. 2001;70:568-78.

Serrano D, Tella JL, Dona'zar JA, Pomarol M. Social and individual features affecting natal dispersal in the colonial lesser kestrel. Ecology. 2003:84:3044-54.

Sorace A, Petrassi F, Consiglio C. Long-distance relocation of nestboxes reduces nest predation by Pine Marten Martes martes. Bird Study. 2004;51:119-24.

Stanback MT, Dervan AA. Within-season nestsite fidelity in Eastern Bluebirds: disentangling effects of nest success and parasite avoidance. Auk. 2001;118:743-5.

Stanback MT, Rockwell EK. Nest-site fidelity in Eastern Bluebirds (Sialia sialis) depends on the quality of alternate cavities. Auk. 2003;120:1029-32.

Styrsky JN. Influence of predation on nest-site reuse by an open-cup nesting neotropical passerine. Condor. 2005;107:133-7.

Sumasgutner P, Vasko V, Varjonen R, Korpimaki E. Public information revealed by pellets in nest sites is more important than ectoparasite avoidance in the settlement decisions of Eurasian Kestrels. Behav Ecol Sociobiol. 2014;68:2023-34.

Switzer PV. Site fidelity in predictable and unpredictable habitats. Evol Ecol. 1993;7:533-55.

Switzer PV. Past reproductive success affects future habitat selection. Behav Ecol Sociobiol. 1997:40:307-12.

Tomás G, Merino S, Moreno J, Morales J. Consequences of nest reuse for parasite burden and female health and condition in blue tit, Cyanistes caeruleus. Anim Behav. 2007;73:805-14.

Vergara P, Aguirre JI, Fargallo JA, Davila JA. Nest-site fidelity and breeding success in White Stork Ciconia ciconia. Ibis. 2006;148:672-7.

Wesolowski T. Anti-predator adaptations in nesting marsh tits Parus palustris: the role of nest-site security. Ibis. 2002;144:593-601.

Wiens JA. Population responses to patchy environment. Annu Rev Ecol Syst. 1976;7:81-120.

Zhou T, Wang HT, Liu Y, Lei FM, Gao W. Patterns of magpie nest utilization by a nesting raptor community in a secondary forest. Prog Nat Sci. 2009;19:1253-9. 